This article was downloaded by: [National Taiwan University]

On: 1 December 2008

Access details: Access Details: [subscription number 905688747]

Publisher Taylor \& Francis

Informa Ltd Registered in England and Wales Registered Number: 1072954 Registered office: Mortimer House, 37-41 Mortimer Street, London W1T 3JH, UK

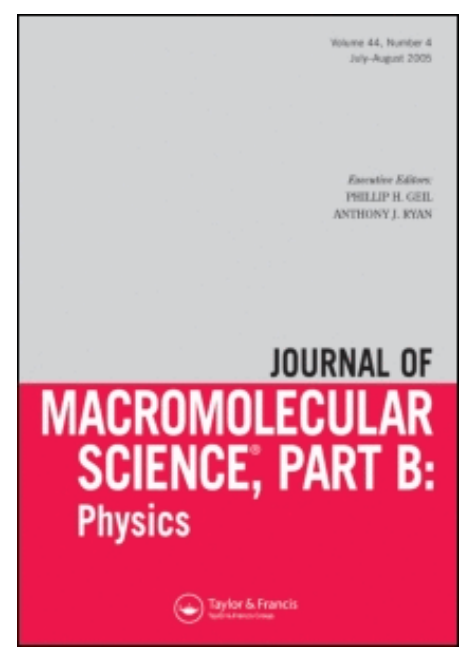

Journal of Macromolecular Science, Part B

Publication details, including instructions for authors and subscription information:

http://www.informaworld.com/smpp/title content=t713375300

\title{
Structural relaxation investigations of glassy polystyrene by radial distribution
} functions

King-Fu Lin a; Shoei-Kin Su a

a Institute of Materials Science and Engineering National Taiwan University, Taipei, Taiwan, ROC

Online Publication Date: 01 May 1994

To cite this Article Lin, King-Fu and Su, Shoei-Kin(1994)'Structural relaxation investigations of glassy polystyrene by radial distribution functions',Journal of Macromolecular Science, Part B,33:2,143 - 154

To link to this Article: DOI: $10.1080 / 00222349408248084$

URL: http://dx.doi.org/10.1080/00222349408248084

\section{PLEASE SCROLL DOWN FOR ARTICLE}

\footnotetext{
Full terms and conditions of use: http://www.informaworld.com/terms-and-conditions-of-access.pdf

This article may be used for research, teaching and private study purposes. Any substantial or systematic reproduction, re-distribution, re-selling, loan or sub-licensing, systematic supply or distribution in any form to anyone is expressly forbidden.

The publisher does not give any warranty express or implied or make any representation that the contents will be complete or accurate or up to date. The accuracy of any instructions, formulae and drug doses should be independently verified with primary sources. The publisher shall not be liable for any loss, actions, claims, proceedings, demand or costs or damages whatsoever or howsoever caused arising directly or indirectly in connection with or arising out of the use of this material.
} 


\title{
Structural Relaxation Investigations of Glassy Polystyrene by Radial Distribution Functions
}

\author{
KING-FU LIN* and SHOEI-KIN SU \\ Institute of Materials Science and Engineering \\ National Taiwan University \\ Taipei, Taiwan 10764, ROC
}

\begin{abstract}
The structural relaxation of an atactic polystyrene under sub- $T_{\mathrm{g}}$ annealing at $50^{\circ} \mathrm{C}$ and at $70^{\circ} \mathrm{C}$ was investigated by the radial distribution function (RDF) derived from its wide-angle $x$-ray scattering (WAXS). By recording the changes in RDF (i.e., $\Delta H(r)$, where $r$ is the radial distance from an arbitrary reference atom) after it had been annealed for a certain period of days, and taking the integration of $\int_{0}^{r} \Delta H(r)^{2} d r$, we found that the atom density within structural domains in a size below $15 \AA$ was changed dramatically, but that the tendency leveled off as annealing proceeded. However, the atom density outside the domains is barely changed by sub- $T_{\mathrm{g}}$ annealing. The size of the domain is similar to the statistical segment length reported in the literature. The behavior of the domains - that the segmental relaxation inside the domains in the initial sub- $T_{\mathrm{g}}$ annealing is unconstrained by their neighbors outside the domains-is also similar to the behavior of the statistical segments. The domains are believed to be composed of a statistical segment across the center, which has about 6 styrene repeat units, and 6 equal-distanced parallel segments tangent to the edge of the domain. On the other hand, as the annealing temperature is closer to the glass transition temperature,
\end{abstract}

* To whom correspondence should be addressed. 
the frozen unstable chain segments reach equilibrium sooner and with less disturbance in their conformation.

Key Words. Polystyrene; Physical aging; RDF; Relaxation; Sub- $T_{\mathrm{g}}$ annealing.

\section{INTRODUCTION}

When an amorphous polymer is quenched through its glass transition temperature to a temperature below its $T_{\mathrm{g}}$, three important structural elementsi.e., the conformation of molecular segments, free volume distribution, and content of free volume-are more or less frozen in the glassy structure. Then, as it is annealed at that temperature, the polymer will relax toward its equilibrium state by rearrangement of its segmental conformations, redistribution of free volume, and decreasing the content of free volume. Although the change of each structural element during sub- $T_{\mathrm{g}}$ annealing has potential to influence the physical and mechanical properties of final products, many researchers have preferred to attribute their changes, such as enthalpy relaxation, creep, etc., to the loss of free volume [1-4]. Nevertheless, there have been reports of discrepancies in predicting the change in creep during sub- $T_{\mathrm{g}}$ annealing in parallel with the changes in free volume and enthalpy relaxation $[5,6]$. Very recently, Lee and McGarry [7] questioned Kovacs' model [2] which predicts the nonequilibrium behavior of a glass based on the total free volume of the structure at any time and temperature.

Furthermore, Wendorff [8] has reported that the thermal density fluctuations for polycarbonate measured by small-angle $x$-ray scattering do not relax toward their equilibrium value during sub- $T_{\mathrm{g}}$ annealing as does the enthalpy relaxation. He suggested that the motions which cause the relaxation are different from the cooperative motions characteristic of the fluid state. Similar results were also reported by Roe and Curro [9] for polystyrene. Thus, the only way to decrease the free volume during sub- $T_{\mathrm{g}}$ annealing is by van der Waal's contraction between adjacent chain segments. In that case, if the frozen chain segments rearrange their conformations substantially during sub- $T_{\mathrm{g}}$ annealing, they would cause a redistribution of free volume so that their influence on the structure should not be ignored if one tries to predict the physical and mechanical properties as functions of annealing time and temperature.

In this regard, to provide direct experimental evidence to show that rearrangements of frozen segmental conformations do occur and that their cooperative motions are retarded during sub- $T_{\mathrm{g}}$ annealing, we monitored the changes in radial distribution function (RDF) for the atactic polystyrene derived from wide-angle $\mathrm{x}$-ray scattering (WAXS) [10]. The change in RDF represents the change in density of atoms $\rho(r)$ in a spherical shell of thickness $d r$ at a radial distance $r$ from 
a reference atom. Thus, the change in local atom density associated with the redistribution of frozen segmental conformations could be detected.

\section{EXPERIMENTAL SECTION}

\section{Material Characterization}

An atactic polystyrene sample was obtained from the $\mathrm{G} / \mathrm{M}$ Company in Taiwan. The atactic structure was verified by infrared spectroscopy (Hitachi 270-30 model; IR) according to Ref. 11. The molecular weight distribution was measured by gel permeation chromatography (Shodex KF-806 model; GPC). The number average molecular weight was $1.235 \times 10^{5} \mathrm{~g} / \mathrm{mol}$ and the weight average molecular weight $2.639 \times 10^{5} \mathrm{~g} / \mathrm{mol}$. The glass transition temperature was $88^{\circ} \mathrm{C}$, measured by differential scanning calorimetry (Du Pont $9900-910$ model; DSC) at a scanning rate of $10^{\circ} \mathrm{C} / \mathrm{min}$ from $60^{\circ} \mathrm{C}$ to $150^{\circ} \mathrm{C}$.

\section{Sample Preparation}

The specimens, in pellet form, were compression molded into circular disks $15 \mathrm{~mm}$ in diameter and $2.5 \mathrm{~mm}$ thick. They were kept in the mold at $150^{\circ} \mathrm{C}$ for at least $30 \mathrm{~min}$ and then quenched by air cooling to room temperature. X-ray diffractions were taken and then they were immediately placed in a desiccator preheated in an oven at $50^{\circ} \mathrm{C}$ (or $70^{\circ} \mathrm{C}$ ). After a chosen time interval of annealing (in days), the specimens were removed for $\mathrm{x}$-ray measurements and then placed back in the desiccator. The time spent for each $\mathrm{x}$-ray measurement was less than $30 \mathrm{~min}$.

\section{X-Ray Measurements and Data Corrections}

X-ray measurements were made on a Philips PW1710 model diffractometer with $\mathrm{CuK}_{\alpha}$ radiation, using a graphite monochromator in the incident beam. The slit system consisted of a divergent slit $1 / 12^{\circ}$ and receiving slit $0.3^{\circ}$. Scattering data were collected by scanning at $0.05^{\circ}$ intervals from $7^{\circ}(2 \theta)$ to $115^{\circ}$. The measured intensity was corrected for background air scattering, absorption, polarization, and multiple scattering. The air scattering was measured by removing the sample from the sample holder and measuring the intensity. The correction for the absorption is based on the method given by Milberg [12]. The correction for multiple scattering was according to the method derived by Warren and Mozzi [13]. The polarization correction was calculated from the standard formula [14]

$$
\text { Polarization }=\frac{1+\cos ^{2} 2 \theta_{\mathrm{M}} \cos ^{2} 2 \theta}{1+\cos ^{2} 2 \theta_{\mathrm{M}}}
$$


where $2 \theta_{M}=26.65^{\circ}$ for the graphite monochromator. The intensities were then corrected as

$$
\begin{gathered}
I_{\text {exp }}=\left(I_{\text {measured }}-I_{\text {air scattering }}\right) /[\text { (absorption) (polarization) } \\
\text { (multiple scattering) }]
\end{gathered}
$$

\section{The RDF}

The RDF of polystyrene has been studied and described in detail by Wecker et al. [10]. A brief review of the RDF method is given here. The RDF, represented by $H(r)$, can be derived from the $\mathrm{x}$-ray data by Fourier transformation:

$$
r H(r)=4 \pi r^{2}\left[\rho(r)-\rho_{0}\right]=(2 r / \pi) \int_{0}^{\infty} i(S)(\sin S r) S d S
$$

where $r$ is the radial distance from an arbitrary reference atom, $\rho(r)$ the atomic density at $r, \rho_{0}$ the average atomic density, $S=4 \pi \sin \theta / \lambda$, and $i(S)$ for a monoatomic material is given by

$$
i(S)=\left[\left(\alpha I_{\exp }-I_{\text {inc }}\right) / f^{2}\right]-1
$$

where $f$ is the scattering factor, $I_{\text {inc }}$ is the incoherent scattering, and $\alpha$ is the normalization constant calculated from the limit method [15] by using the equation

$$
-2 \pi \rho_{0} Z^{2}=\alpha \int_{0}^{S_{\max }} I_{\exp } S^{2} d S-\int_{0}^{S_{\max }} S^{2}\left(f^{2}+I_{\text {inc }}\right) d S
$$

where $Z$ is the atomic number of the atom. For a multiatomic system, $i(S)$ is given by

$$
i(S)=\left[\left(\alpha I_{\exp }-I_{\mathrm{inc}}\right)-\sum_{i=1}^{n} x_{i}\left(f_{i}\right)^{2}\right] /\left[\sum_{i=1}^{n} x_{i} f_{i}\right]^{2}
$$

where $n$ is the number of species in the system, $x_{i}$ is the atomic fraction of the species $i$, and $f_{i}$ is the scattering factor of the species $i$.

When Eq. (3) is integrated, the loss of data between $s_{\max }$ and $\infty$ will cause a termination error, which can be seen from the presence of spurious ripples superimposed on the RDF data. To reduce the termination error, the sampled transform method given by Lovell et al. [16] was used with termination at a minimum point, $s_{\max }=6.9 \AA^{-1}$.

\section{RESULTS AND DISCUSSION The Change of RDF During Sub- $T_{g}$ Annealing}

The corrected intensity $\left(I_{\text {exp }}\right)$ of a quenched polystyrene sample as a function of scattering angle $(2 \theta)$ is shown in Fig. 1. Its transformed RDF has four 


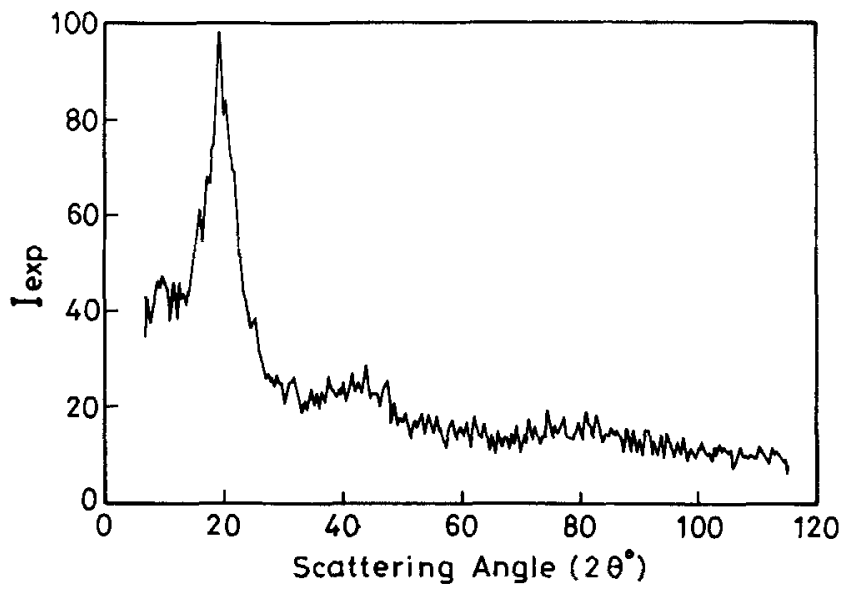

FIG. 1. Corrected intensity of a quenched polystyrene sample as a function of scattering angle.

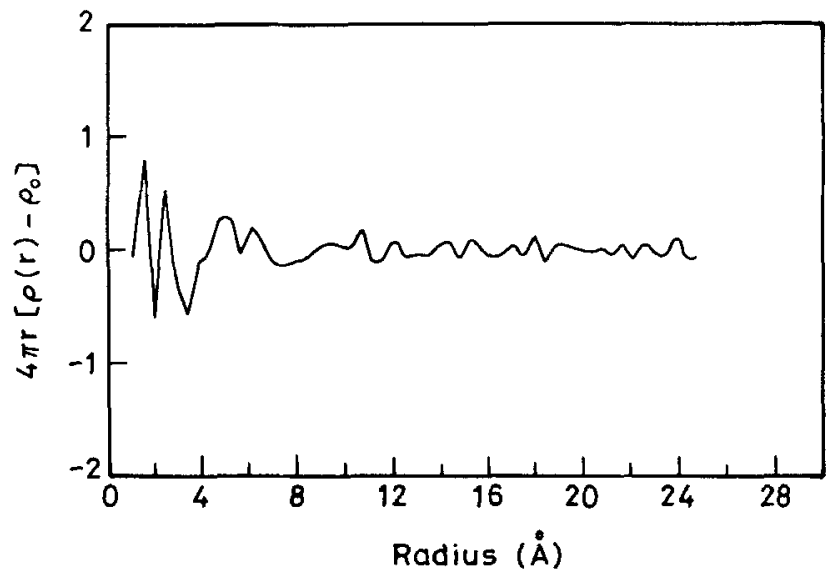

FIG. 2. RDF of a quenched polystyrene sample.

prominent peaks, at $1.5,2.5,5$, and $6.2 \AA$; and several weak peaks at $4,9.3$, 10.6, 12.1 $\AA$, and so on, as shown in Fig. 2. Similar RDF data have also been reported by Wecker et al. [10] for quenched atactic polystyrene. The peak at 1.5 $\AA$ corresponds to the bonded nearest-neighbor C-C distance, whereas that at 2.5 $\AA$ corresponds to the second nearest-neighbor bonded distances. The peaks located at $r$ greater than $2.5 \AA$ are broad and their origins are more complicated, because they involve many intramolecular and intermolecular spacings. 


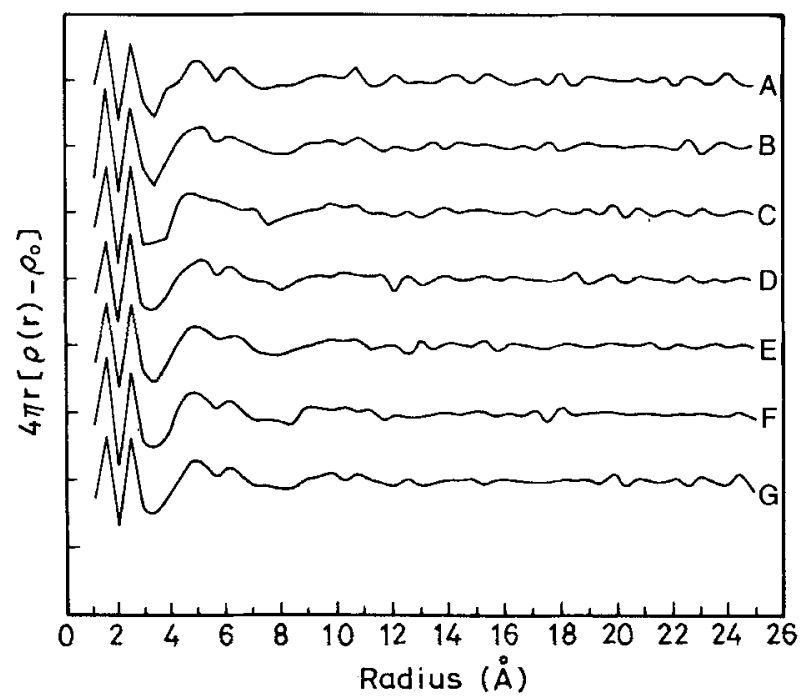

FIG. 3. RDF of the polystyrene sample after being quenched and annealed at $50^{\circ} \mathrm{C}$ for various times: A, $0 ; \mathrm{B}, 7$; C, 15; D, 22; E, 29; F, 36; and G, 50 days.

Since about three-fourths of the mass of the polystyrene repeat unit are phenyl rings, their positions related to the reference atom are an important factor in determining the peak positions at $r$ greater than $2.5 \AA$. Wecker et al. [10] calculated the RDF of isotactic polystyrene based on its crystal structure determined by Natta and Corradini [17] and found that the peaks covering the range of 3.4 to $5.2 \AA$ involve 164 spacings, of which 86 spacings are interchain; all but 10 of the interchain spacings are between phenyl atoms and all but 20 of the intrachain spacings are between phenyl and main chain atoms. The peaks covering the range of 5.2 to $8 \AA$ involve nearly 700 spacings, two-thirds of which are interchain. The peaks beyond $8 \AA$ are mostly contributed by the intermolecular spacings.

The RDF for the quenched sample after annealing at $50^{\circ} \mathrm{C}$ for $7,15,22$, 29,36 , and 50 days is shown in Fig. 3. The peak at $1.5 \AA$ did not change its shape and position as the specimen was annealed, indicating that the length of $\mathrm{C}-\mathrm{C}$ bonds was not changed. As to the peak at $2.5 \AA$, it became narrower during annealing although the position did not change. This peak is mostly contributed by the $\mathrm{C}-\mathrm{C}-\mathrm{C}$ bonds. When the sample was quenched to below $T_{\mathrm{g}}$, some unstable segmental conformations would be frozen into the glassy structure. As a result, the bond angle of certain $\mathrm{C}-\mathrm{C}-\mathrm{C}$ bonds would be under strain. During sub- $T_{\mathrm{g}}$ annealing, the strained bond angles gradually relaxed toward their stable position, resulting in the sharper peak at $2.5 \AA$. Moreover, the sharp valley at 


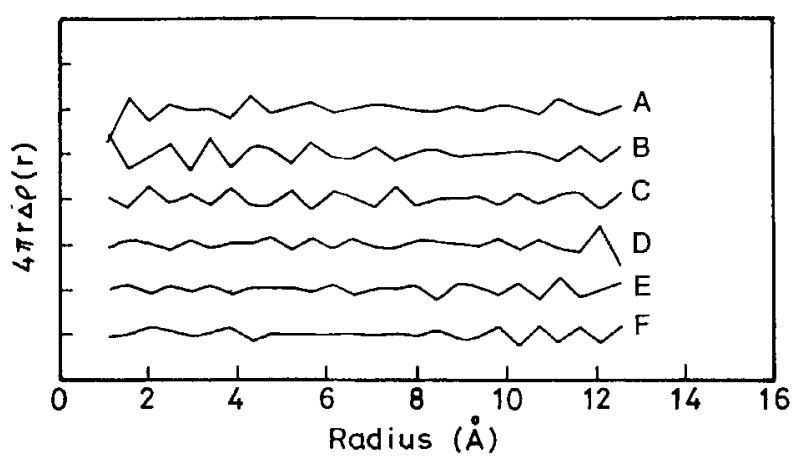

FIG. 4. $\Delta H(r)$ of the polystyrene sample between two sequential annealing periods at $50^{\circ} \mathrm{C}$ : A, 7 days-quenched; B, 15-7 days; C, 22-15 days; D, 29-22 days; E, 36-22 days; and $\mathrm{F}, 50-36$ days.

$3.3 \AA$ right after the peak at $2.5 \AA$ became shallower and the shoulder at 3.9 $\AA$ disappeared. According to the previous analysis on the RDF of polystyrene [10], these changes are contributed more by the change of intramolecular spacings (i.e., the change of polymer segmental conformations) than the intermolecular spacings.

On the other hand, the change of the broad peaks in the range from 4.5 to $7.5 \AA$ during sub- $T_{\mathrm{g}}$ annealing is contributed more by changes in the intermolecular spacings. However, since their spacings are still small, the change of intermolecular spacings in this range should be affected by the conformations' rearrangement of neighboring segments.

So far, we have discussed the changes of the major peaks in RDF during sub- $T_{\mathrm{g}}$ annealing. To see the change of the entire RDF patterns, the difference in RDF, $\Delta H(r)=4 \pi r \Delta \rho(r)$, where $\Delta \rho(r)$ is the difference in atom density at $r$, of the specimen between two sequential annealing stages was calculated; they are shown in Fig. 4. From the figure, it can be seen that the change in RDF from 0 to $8 \AA$ was pronounced in the initial 15 days of sub- $T_{\mathrm{g}}$ annealing at $50^{\circ} \mathrm{C}$. However, the amount of change decreased greatly after the specimen had been annealed for 22 days. To estimate the number of atoms affected by sub- $T_{\mathrm{g}}$ annealing in a distance $r$ from a reference atom, we calculated the $\Delta H(r)$ between two alternate annealing stages and integrated the $\int_{0}^{r} \Delta H(r)^{2} d r=\int_{0}^{r}[4 \pi r \Delta \rho(r)]^{2}$ $d r$. The integration of $\int_{0}^{r} \Delta H(r)^{2} d r$ provides information about the accumulated change in atom density as a function of distance $r$ regardless of whether the change is increased or decreased. Figure 5 shows the plot of $\int_{0}^{r} \Delta H(r)^{2} d r$ versus $r$ for every other annealing stage. As seen in the figure, the atom density changed dramatically inside the domains of $7.5 \AA$ radius during sub- $T_{\mathrm{g}}$ annealing but the 


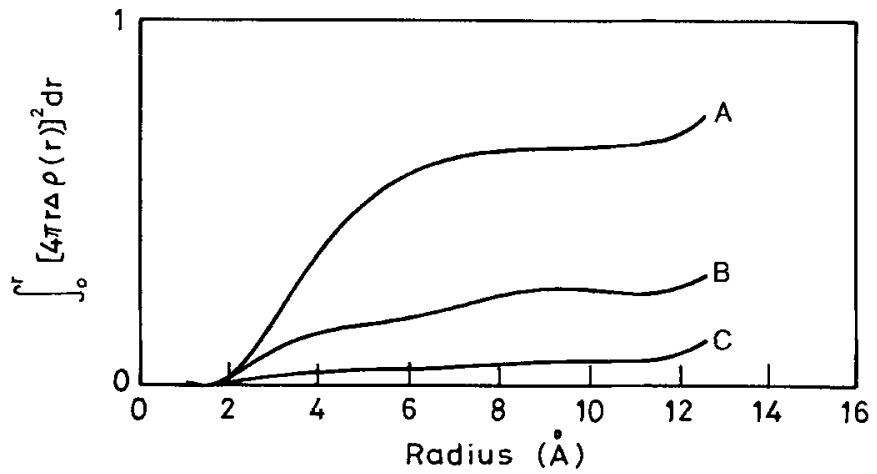

FIG. 5. $\int_{0}^{r} \Delta H(r)^{2} d r$ versus $r$ for the polystyrene sample between two alternate annealing periods at $50^{\circ} \mathrm{C}$ : A, 15 days-quenched; B, 29-15 days; and C, 50-29 days.

tendency leveled off as annealing proceeded. However, the density outside the domains barely changed during sub- $T_{\mathrm{g}}$ annealing. This could result from the intermolecular spacings wider than $7.5 \AA$ being so wide that the rearrangements of segmental conformations do not affect their spacings. According to the definition of RDF, the affected domains in the structure are spheres with an average diameter $15 \AA$, whose centers are "average" reference atoms.

It has been reported that the statistical segment length of atactic polystyrene is in a range from 5 to $20 \AA$, measured by the neutron scattering technique [18]. The statistical segments in a polymer chain can be thought of as the average length of freely rotating straight segments of a randomly coiled chain [5]. By definition, the motion of statistical segments is not constrained by their neighbors. Since the size of domains affected by sub- $T_{\mathrm{g}}$ annealing is in a range similar to the statistical segment length and since their behavior-that the atom density outside the domains is not affected by the change inside-is also similar to that of the statistical segments, we suggested the domains are composed of the statistical segments. By taking the $\mathrm{C}-\mathrm{C}$ bond length as $1.54 \AA$ and the $\mathrm{C}-\mathrm{C}-\mathrm{C}$ bond angle as $109^{\circ}$ [19], the length of a styrene repeat unit in a polystyrene molecular chain can be calculated as $2.52 \AA$. Thus, the statistical segments in the domains should have about six repeat units if a planar zigzag conformation is assumed. Moreover, it has been suggested that the chain segments in the glassy polystyrene tend to pack parallel to each other $[10,20]$. The interchain spacing was also reported as $7.3 \AA$ according to the crystal structure of isotactic polystyrene [10, 17]. Therefore, it is believed that the domains are composed of a statistical segment across their center and six parallel segments tangent to their edges. The distances between any two adjacent segments are the same and equal to the radius of the domain. On the other hand, the apparently unchanged atom density outside the 


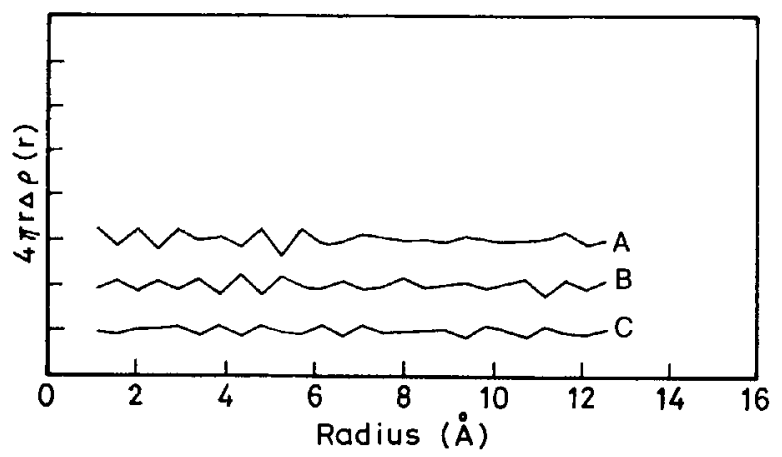

FIG. 6. $\Delta H(r)$ of the polystyrene sample between two sequential annealing periods at $70^{\circ} \mathrm{C}$ : A, 7 days-quenched; B, 14-7 days; and C, 21-14 days.

domains is consistent with the reported small-angle $\mathrm{x}$-ray scattering results for the amorphous polymer indicating that the large-scale density fluctuations are not affected by sub- $T_{\mathrm{g}}$ annealing [8,9]. This implies that the cooperative motions of statistical segments during sub- $T_{\mathrm{g}}$ annealing are prohibited or retarded. A possible way to decrease the specific volume is by van der Waals contraction between adjacent chain segments. It was also reported for epoxy resins that the local small-scale contraction in an epoxy network is easier and faster than that of the entire network during sub- $T_{\mathrm{g}}$ annealing [21], for the contraction of the latter should be by way of the van der Waals interactions between the adjacent chain segments.

\section{Effects of Annealing Temperature}

To investigate the effects of annealing temperature on the RDF of polystyrene, a quenched sample was annealed at $70^{\circ} \mathrm{C}$ and the $R D F$ determined at 7,14 , and 21 days. Figure 6 shows their difference in RDF [i.e., $\Delta H(r)$ ] between two sequential annealing periods. As seen in the figure, the change in RDF is significant in the first 7 days of sub- $T_{\mathrm{g}}$ annealing. However, with further annealing the change in RDF from 7 days to $\mathbf{1 4}$ days was not only less significant but almost in the opposite direction compared to the first stage of annealing up to $r=6 \AA$. The reason behind this was not clear. However, according to the previous study on sub- $T_{\mathrm{g}}$ annealing of epoxy resins [21], the local small-scale shrinkage is faster than that of the entire network, but the slow shrinkage of the latter in the latter stage of annealing decreases the density difference between the local and entire epoxy networks produced in the first stage of annealing. Accordingly, the opposite direction of change in the RDF of polystyrene after 7 days of annealing at $70^{\circ} \mathrm{C}$ might be 


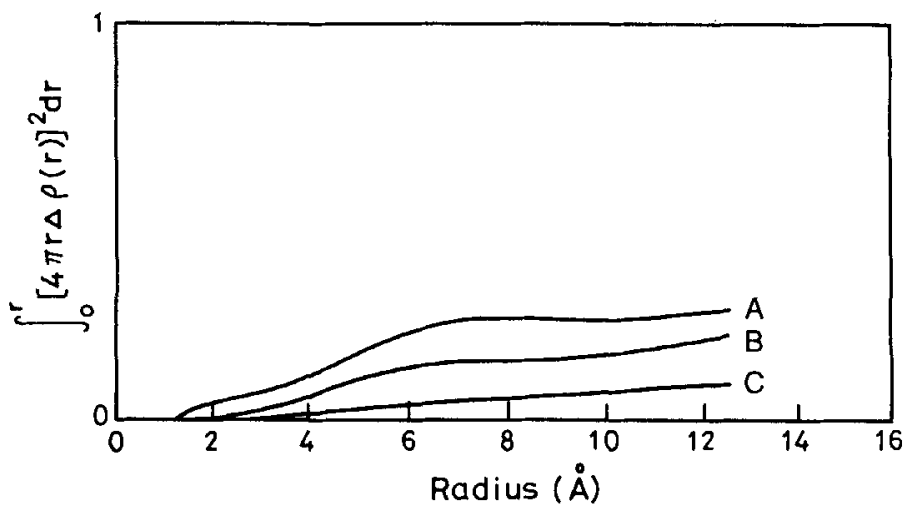

FIG. 7. $\int_{0}^{r} \Delta H(r)^{2} d r$ versus $r$ for the polystyrene sample between two sequential annealing periods at $70^{\circ} \mathrm{C}: \mathrm{A}, 7$ days-quenched; $\mathrm{B}, 14-7$ days; and $\mathrm{C}, 21-14$ days.

due to the fact that the annealing is dominated by the van der Waals contraction between adjacent chain segments, relieving some of the previous rapid contraction of chain segments themselves. Nevertheless, the change in RDF by sub$T_{\mathrm{g}}$ annealing leveled off after 14 days, sooner than that at $50^{\circ} \mathrm{C}$. In order to estimate the accumulated change in atom density as a function of distance $r$ regardless of whether the change is increased or decreased, we calculated $\int_{\text {- }}^{r}$ ${ }_{0} \Delta H(r)^{2} d r$ from the data shown in Fig. 6. The results given in Fig. 7 show that the change in atom density is less significant and reaches equilibrium sooner than at $50^{\circ} \mathrm{C}$, although the size of the domain in which the atom density changes is not noticeably changed. The $T_{\mathrm{g}}$ of our polystyrene sample measured by DSC is $88^{\circ} \mathrm{C}$, as shown in Fig. 8. The smaller change in atom density during annealing at $70^{\circ} \mathrm{C}$ than at $50^{\circ} \mathrm{C}$ suggested that, as the annealing temperature is closer to the glass transition region of the sample, the frozen unstable chain segments reach equilibrium with less change or disturbance in their conformation.

On the other hand, according to Flory [22], the temperature coefficient of the mean square unperturbed end-to-end distance-i.e., $d \ln \left\langle\bar{r}^{2}\right\rangle_{0} / d T-$ for atactic polystyrene is $4 \times 10^{-4} \mathrm{deg}^{-1}$. Thus, if the temperature coefficient of statistical chain lengths is similar to that of the mean square unperturbed end-to-end distance, the difference in statistical chain length between $50^{\circ} \mathrm{C}$ and $70^{\circ} \mathrm{C}$ would be less than $1 \%$. This might explain why the size of the domain in which the atom density changed during sub- $T_{\mathrm{g}}$ annealing is not noticeably affected by the change of annealing temperature from $50^{\circ}$ to $70^{\circ} \mathrm{C}$. 


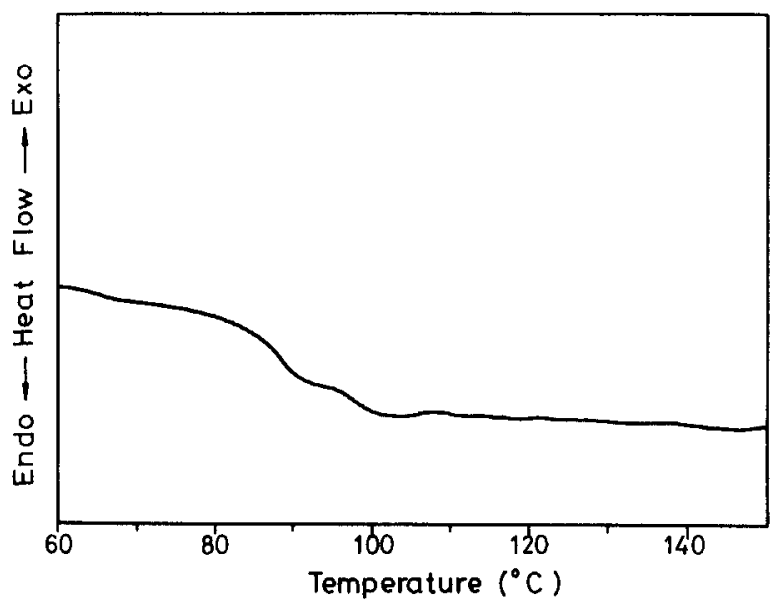

FIG. 8. DSC spectrum of a polystyrene sample.

\section{CONCLUSIONS}

By using the RDF method we were able to detect the changes of atom density associated with the segmental relaxation of an atactic polystyrene during sub$T_{\mathrm{g}}$ annealing. The domain size in which those changes took place is similar to the statistical segment length and barely affected by the change of annealing temperature from $50^{\circ}$ to $70^{\circ} \mathrm{C}$. Furthermore, the intensity of change in atom density inside the domains in the initial sub- $T_{\mathrm{g}}$ annealing is increased by increasing the temperature difference between the glass transition and the annealing temperature. However, the change of atom density outside the domains was almost nil during sub- $T_{\mathrm{g}}$ annealing. Thus, the relaxations of frozen unstable chain conformations are considered to be the primary factor on the molecular scale in the initial sub- $T_{\mathrm{g}}$ annealing.

\section{ACKNOWLEDGMENT}

K.-F. Lin and S.-K. Su wish to acknowledge the financial support for this work from the National Science Council in Taiwan, ROC (Grant NSC80-0405-E002-12).

\section{REFERENCES}

1. L. C. E. Struik, Physical Aging of Amorphous Polymers and Other Materials, Elsevier, New York, 1978. 
2. A. J. Kovacs, Fortschr. Hochpolym. Forsch., 3, 394 (1963).

3. S. E. B. Petrie, J. Polym. Sci. Polym. Phys. Ed., 10, 1255 (1972).

4. A. Bondi, Physical Properties of Molecular Crystals, Liquids and Glasses, Wiley, New York, 1968.

5. P. H. Geil, Ind. Eng. Chem. Prod. Res. Dev., 14, 59 (1975).

6. R.-J. Roe and G. M. Millman, Polym. Eng. Sci., 23, 318 (1983).

7. H. H. D. Lee and F. J. McGarry, J. Macromol. Sci.-Phys., B30(3), 185 (1991).

8. J. H. Wendorff, J. Polym. Sci. Polym. Lett. Ed., 17, 765 (1979).

9. R.-J. Roe and J. J. Curro, Macromolecules, 16, 429 (1983).

10. S. M. Wecker, T. Davidson, and J. B. Cohen, J. Mater. Sci., 7, 1249 (1972).

11. M. Kobayashi, K. Akita, and H. Tadokoro, Makromol. Chem., 118, 324 (1968).

12. M. E. Milberg, J. Appl. Phys., 48, 64 (1958).

13. B. E. Warren and R. L. Mozzi, Acta Cryst., 21, 459 (1966).

14. C. S. Wang and G. S. Y. Yeh, J. Macromol Sci.-Phys., B15(1), 107 (1978).

15. K. Furukawa, Rep. Prog. Phys., 25, 395 (1962).

16. R. Lovell, G. R. Mitchell, and A. H. Windle, Acta Cryst., A35, 598 (1979).

17. G. Natta and P. Corradini, Makromol. Chem., 16, 77 (1955).

18. D. G. H. Ballard, J. Schelten, and G. D. Wignall, Paper Presented at IUPAC Meeting, Aberdeen, September 1973.

19. P. J. Flory, Principles of Polymer Chemistry, Cornell University Press, Ithaca, NY, 1953, p. 618.

20. H. G. Kilian and K. Boueke, J. Polym. Sci., 58, 311 (1962).

21. J. Mijovic and K.-F. Lin, J. Appl. Polym. Sci., 32, 3211 (1986).

22. P. J. Flory, Statistical Mechanics of Chain Molecules, Wiley-Interscience, New York, 1969, p.39.

Received by Editor January 25, 1993

Accepted by Editor June 14, 1993 